\title{
Maximum Torque per Voltage Flux-Weakening strategy with speed limiter for PMSM drives
}

\author{
Carlos Miguel-Espinar, Daniel Heredero-Peris, Gabriel Gross, Marc Llonch-Masachs, \\ and Daniel Montesinos-Miracle, Fellow Member, IEEE
}

\begin{abstract}
This paper presents an enhanced Flux Weakening (FW) control scheme for Permanent Magnet Synchronous Motors (PMSMs), focused on electric vehicle applications. The novelty of the proposed algorithm is the integration in a unified scheme of both the accelerator pedal as torque reference and the cruise speed limiter (CSL) as speed limit, without interfering between them until this limit is achieved. The dq-axis current references are calculated from the proposed algorithm by using a polar coordinate system and a per-unit system. The latter is based on the characteristic machine parameters which aim to ease and simplify the algorithm implementation. Moreover, it takes advantage of the smooth transition between the Low Back Electromotive Force (LBEF) zone and the FW zone thanks to a voltage loop which changes the current-vector angle. Another fundamental merit of the proposed scheme is its capacity to work in all the dq-plane throughout the Maximum Torque per Ampere (MTPA), Constant Torque (CT), Current and Voltage Limit (CVL), Maximum Torque per Voltage (MTPV) and Constant Speed (CS) strategies without switching the algorithm. Simulations and experimental results from a real exterior-rotor Interior Permanent Magnet Synchronous Motor (IPMSM) direct-drive emotorbike verify the effectiveness of the proposed method.
\end{abstract}

Index Terms-Flux Weakening, Maximum Torque per Voltage, Permanent magnet motors, Torque control, Velocity control.

\section{INTRODUCTION}

$\mathbf{N}$ OWADAYS, the use of mild-hybrid and full-electric vehicles is rapidly increasing due to the importance of reducing greenhouse gas emissions. Another significant tendency in the automotive industry is the necessity to provide torque assistance and torque boosting in the powertrain. Moreover, the newest electric traction requires motors with high torque at low speeds and wide speed range at constant power. Based on the requirements mentioned above, a Permanent Magnet Synchronous Motor (PMSM) is an adequate type for this application [1].

Below the nominal speed, the Maximum Torque per Ampere (MTPA) strategy is used to minimize the required current. When the speed increases, the back electromotive force does so and, from a certain speed, it is mandatory to diminish the

Manuscript received January 14, 2020; revised March 2, 2020, April 25, 2020, and July 8, 2020; accepted August 11, 2020.

C. Miguel-Espinar, D. Heredero-Peris, G. Gross, M. Llonch-Masachs and D. Montesinos $\mathrm{i}$ Miracle are with the CITCEA-UPC (Centre d'Innovació Tecnològica en Convertidors Estàtics i Accionaments), Departament d'Enginyeria Elèctrica, Universitat Politècnica de Catalunya, ETS d'Enginyeria Industrial de Barcelona, Barcelona, 08028, Spain (e-mail: carlos.miguel@citcea.upc.edu; daniel.heredero@citcea.upc.edu; gabriel.gross@citcea.upc.edu; marc.llonch@citcea.upc.edu; montesinos@citcea.upc.edu) stator magnet flux through the stator currents, increasing the negative $d$-axis current. Thenceforward, the motor is working in the denominated Flux Weakening (FW) zone.

By the authors' best knowledge, literature shows several FW algorithms working either at Constant Torque (CT) and Current and Voltage Limits (CVL) zones. These techniques have been widely classified and analyzed in [2], citing the most important characteristics of each one: Analytical Direct Calculation [3], [4], Direct Open Loop Algorithm with Experimental Look Up Tables (LUT) [5]-[7], Single Current Regulator (SCR) [8]-[10], Torque and Flux Control Method with LUT [11], [12], Unified Direct Flux Vector Control (UDFVC) in the stator flux frame [13], [14] and Vector Current Control (VCC) [15]-[21]. It should be highlighted that for electric vehicles, the need for a wide constant power speed range demands the control to work in the Maximum Torque per Voltage (MTPV) zone, so these methods are discarded.

Some authors have adapted the previously cited methods with the possibility to achieve the MTPV zone: Analytical Direct Calculation [22]-[24], Direct Open Loop Algorithm with Simulated or Experimental LUT [25]-[27], Torque and Flux Control Method with LUT [25], [28]-[30]. However, VCC is the most common one [31]-[38]. These methods may also be divided into three type of regulation: on the voltage magnitude [32], [34], [36]-[38], on the voltage error [31], [35] and on the duty cycles [33].

The main drawback of Analytical Direct Calculation is its parameter-variation sensitiveness, especially if high currents are required. Moreover, these control algorithms for an Interior Permanent Magnet Synchronous Motor (IPMSM) take many calculations in real-time, increasing the burden of the microcontroller. LUTs in Direct Open Loop and Torque and Flux Control Methods are convenient for considering both the magnetic saturation and resistor voltage drop, but they depend on previous experimental results or Finite Element Analysis.

In this paper, a VCC method that controls the voltage norm is used. The main characteristics of the analyzed methods are listed in Table I. Bologniani in [20] suggested that calculating the FW reference with the current angle, instead of the $d$ axis current, maximizes the dynamic performance. So, a lower voltage margin is considered, and high torque and efficiency are achieved. In none of the analyzed algorithms torque and speed references are contemplated in the same scheme.

As a result, this paper proposes an enhanced algorithm that considers the requirements of electric vehicles, converting the accelerator pedal and the cruise speed limiter (CSL) in reference signals of a unified scheme. This algorithm lets the 
TABLE I

MTPV ALGORITHMS COMPARISON

\begin{tabular}{cccccc}
\hline \hline Reference & $\begin{array}{c}\text { Reference } \\
\text { System }\end{array}$ & $\begin{array}{c}\text { Coordinate } \\
\text { System }\end{array}$ & $\begin{array}{c}\text { Transition } \\
\text { to FW }\end{array}$ & $\begin{array}{c}\text { Output } \\
\text { Voltage Controller }\end{array}$ & $\begin{array}{c}\text { Reference } \\
\text { Signal }\end{array}$ \\
\hline$[32]$ & Real & Cartesian & Switched & $d q$-axis current & Speed \\
{$[34]$} & Real & Cartesian & Continuous & $d$-axis current & Speed \\
{$[36]$} & Real & Cartesian & Switched & $d$-axis current & Speed \\
{$[37]$} & Real & Cartesian & Continuous & $d$-axis current & Torque \\
{$[38]$} & Per-unit & Polar & Continuous & angle current & Speed \\
\hline \hline
\end{tabular}

vehicle have the dynamics of the torque control until the speed limit is reached, by not interfering with the current controllers until this threshold is achieved. It smoothly changes to a FW zone, letting the motor work in all the possible trajectories: MTPA, CT, CVL, MTPV, and Constant Speed (CS). This soft transition is done by an explicit control scheme that avoids switching among the different trajectories. This transition is achieved thanks to a voltage loop controller, which gives the angle current variation from the MTPA curve to the FW zone. Moreover, it takes advantage of a per-unit system based on the motor parameters to reduce the computational burden of a fixed-point microcontroller in real-time, making it more attractive for industrial applications.

The content of the paper is organized in six sections. In Section II, a per-unit PMSM model is presented, as well as all the possible trajectories below and above the nominal speed. In Section III, the proposed FW strategy is explained. In Section IV and V, the simulation and experimental results are presented for a real exterior-rotor Interior Permanent Magnet Synchronous Motor (IPMSM) direct-drive e-motorbike. Finally, Section VI details the conclusion reached after this research was conducted.

\section{Achievable Operating Points}

In Section II-A, a per-unit PMSM model and its electrical limits are presented. In Section II-B, the trajectory at low speed is described, and the base speed is defined. Finally, in Section II-C, all the FW trajectories are analyzed.

\section{A. PMSM per-unit model in the Cartesian coordinate system}

In accordance with [39], the PMSM electrical dynamic equations referred to the synchronous rotor frame with the $d$-axis aligned to the rotor flux, and by implementing the Park transformation which maintains the current and voltage modulus invariant, are

$$
\begin{gathered}
v_{d}(t)=R_{\mathrm{s}} i_{d}(t)+L_{d} \frac{d i_{d}(t)}{d t}-\omega_{\mathrm{e}}(t) L_{q} i_{q}(t) \\
v_{q}(t)=R_{\mathrm{s}} i_{q}(t)+L_{q} \frac{d i_{q}(t)}{d t}+\omega_{\mathrm{e}}(t) L_{d} i_{d}(t)+\omega_{\mathrm{e}}(t) \lambda_{\mathrm{m}},
\end{gathered}
$$

where $v_{d}(t), v_{q}(t), i_{d}(t)$ and $i_{q}(t)$ are the time-dependent voltage and current $d q$ components, $L_{d}$ and $L_{q}$ are the motor inductance at the $d q$-axis, $\lambda_{\mathrm{m}}$ is the flux linkage due to the spinning of magnets, $R_{\mathrm{S}}$ is the winding phase resistance and $\omega_{\mathrm{e}}(\mathrm{t})$ is the time-dependent electrical speed.

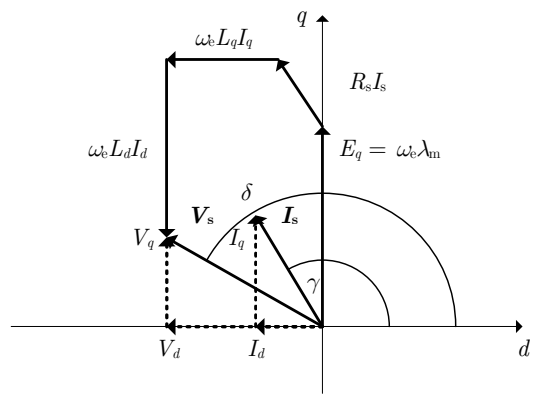

Fig. 1. Phasor diagram in $d q$-axis.

At steady-state conditions the voltage equations are simplified as

$$
\begin{gathered}
V_{d}=R_{\mathrm{s}} I_{d}-\omega_{\mathrm{e}} L_{q} I_{q} \\
V_{q}=R_{\mathrm{s}} I_{q}+\omega_{\mathrm{e}} L_{d} I_{d}+\omega_{\mathrm{e}} \lambda_{\mathrm{m}},
\end{gathered}
$$

where $V_{d}, V_{q}, I_{d}$ and $I_{q}$ are the non time-dependent voltage and current $d q$ components, and $\omega_{\mathrm{e}}$ is the non time-dependent speed.

The relationship between mechanical and electrical speed in a PMSM is expressed as

$$
\omega_{\mathrm{m}}=\frac{\omega_{\mathrm{e}}}{\mathrm{pp}},
$$

where $\omega_{\mathrm{m}}$ is the mechanical speed and pp is the pair of poles.

Equations (3) and (4) may be represented in a diagram phasor as in Fig. 1. The proposed method is based on controlling the norm $\left(I_{\mathrm{s}}\right)$ and angle current $(\gamma)$ instead of the conventional methods whose aim is to control $I_{d}$ and $I_{q}$. It has to be noted that $\gamma$ and $\delta$ (voltage angle) are referred with reference to the positive $d$-axis.

The electromagnetic torque $\left(T_{\mathrm{em}}\right)$ is expressed as

$$
T_{\mathrm{em}}=\frac{3}{2} \mathrm{pp}\left(\lambda_{\mathrm{m}} I_{q}+\left(L_{d}-L_{q}\right) I_{d} I_{q}\right) .
$$

A per-unit system is used to simplify the FW analysis. Base values are listed in Table II. The subscript $\mathrm{N}$ indicates the nominal value of the electrical speed. Fundamentally, the base current is defined as the short-circuit current $\left(I_{\mathrm{sc}}\right)$ of the machine. This current represents the flux generated in the stator by the winding currents with the same direction and value as the flux linkage of the permanent magnets. Moreover, the base torque is the corresponding value when the motor is considered an SPMSM and the base current is equal to $I_{\mathrm{sc}}$. In Table II, the parameter $\xi$ is defined as the saliency ratio.

Achievable operating points are restricted according to the current and voltage limits. The maximum available current $\left(i_{\mathrm{s}, \max }\right)$ is expressed as

$$
\sqrt{i_{d}^{2}+i_{q}^{2}}=i_{s} \leq i_{\mathrm{s}, \max }=\frac{\min \left\{I_{\mathrm{motor}, \max }, I_{\mathrm{inv}, \max }, I_{\mathrm{bat}, \max }\right\}}{I_{\mathrm{b}}},
$$

where $i_{d}$ and $i_{q}$ are the non time-dependent current $d q$ components expressed in the per-unit system, $i_{s}$ is the modulus current vector in the per-unit system, $I_{\text {motor,max }}$ is the maximum 
TABLE II

BASE VALUES FOR AN SPMSM AND AN IPMSM

\begin{tabular}{|c|c|c|c|}
\hline Symbol & Quantity & SPMSM $^{a}$ & $\operatorname{IPMSM}^{b}$ \\
\hline$\lambda_{\mathrm{b}}$ & base flux linkage & \multicolumn{2}{|c|}{$\lambda_{\mathrm{m}}$} \\
\hline$\omega_{\mathrm{b}}$ & base electrical rotational speed & \multicolumn{2}{|c|}{$\omega_{\mathrm{e}, \mathrm{N}}$} \\
\hline$I_{\mathrm{b}}$ & base current & $I_{\mathrm{sc}}=\frac{\lambda_{\mathrm{m}}}{L}$ & $I_{\mathrm{sc}}=\frac{\lambda_{\mathrm{m}}}{L_{d}}$ \\
\hline$V_{\mathrm{b}}$ & base voltage & \multicolumn{2}{|c|}{$\lambda_{\mathrm{m}} \omega_{\mathrm{e}, \mathrm{N}}$} \\
\hline$Z_{\mathrm{b}}$ & base impedance & $\omega_{\mathrm{e}, \mathrm{N}} L$ & $\omega_{\mathrm{e}, \mathrm{N}} L_{d}$ \\
\hline$T_{\mathrm{b}}$ & base torque & $\frac{3}{2} \mathrm{pp} \frac{\lambda_{\mathrm{m}}^{2}}{L}$ & $\frac{3}{2} \mathrm{pp} \frac{\lambda_{\mathrm{m}}^{2}}{L_{d}}$ \\
\hline$\xi$ & saliency ratio & 1 & $\frac{L_{q}}{L_{d}}$ \\
\hline
\end{tabular}

${ }^{a}$ SPMSM: $L_{d}=L_{q}=L .{ }^{b}$ IPMSM: $L_{d} \neq L_{q}$

motor current, $I_{\mathrm{inv}, \max }$ is the maximum inverter current, $I_{\mathrm{bat}, \max }$ is the maximum battery current, and $I_{\mathrm{b}}$ is the base current value indicated in Table II. So, $i_{\mathrm{s}, \max }$, as well as $i_{\mathrm{s}}$, can be higher or less than 1 , depending on if the electrical and thermal battery, converter and motor limits are higher or less than $I_{\mathrm{sc}}$.

The maximum available voltage $\left(v_{\mathrm{s}, \max }\right)$ is expressed as

$$
\sqrt{v_{d}^{2}+v_{q}^{2}}=v_{s} \leq v_{\mathrm{s}, \max }=\frac{V_{\mathrm{bat}}}{\sqrt{3} V_{\mathrm{b}}},
$$

where $v_{d}$ and $v_{q}$ are the non time-dependent voltage $d q$ components expressed in the per-unit system, $v_{s}$ is the modulus voltage vector in the per-unit system, $V_{\text {bat }}$ is the battery voltage, and $V_{\mathrm{b}}$ is the base voltage value indicated in Table II. A Space Vector Pulse Width Modulation (SVPWM) strategy is chosen in this paper.

Expressing (3) and (4) in the per-unit system and neglecting the resistor voltage drop, (8) yields to

$$
\frac{\left(i_{d}+1\right)^{2}}{\left(\frac{v_{\mathrm{s} \text { max }}}{\Omega_{\mathrm{c}}}\right)^{2}}+\frac{i_{q}^{2}}{\left(\frac{v_{\mathrm{s} \text { max }}}{\Omega_{\mathrm{e}} \xi}\right)^{2}} \leq 1,
$$

where $\Omega_{\mathrm{e}}$ is the electrical speed in the per-unit system. Also, the electromagnetic torque in the per-unit system $\left(\tau_{\mathrm{em}}\right)$ is expressed as

$$
\tau_{\mathrm{em}}=i_{q}\left[1+(1-\xi) i_{d}\right] .
$$

Fig. 2 and Fig. 3 depict the characteristic curves for an SPMSM and an IPMSM, respectively. The current limit (7) is seen as a circle centered in the coordinates $\left(i_{d}, i_{q}\right)=(0,0)$, with a radius equal to $i_{\mathrm{s}}$.

The voltage limit (9), in the case of an SPMSM, depicts a circle centered in the coordinates $\left(i_{d}, i_{q}\right)=(-1,0)$ and with a radius equal to $\frac{v_{\mathrm{s}}}{\Omega_{\mathrm{e}}}$. In the case of an IPMSM, (9) describes an ellipse with the same center, in which semi-major and semi-minor axes are equal to $\frac{v_{\mathrm{s}}}{\Omega_{\mathrm{e}}}$ and $\frac{v_{\mathrm{s}}}{\Omega_{\mathrm{e}} \xi}$, respectively. If the resistor voltage drop is considered, the voltage curve suffers a translation and a rotation depending on $i_{d}$ and $i_{q}$ values, but this topic is out of the scope of this paper.

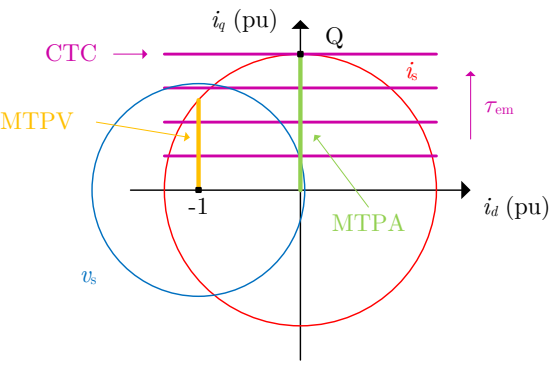

Fig. 2. Characteristic curves for SPMSMs with $i_{\mathrm{s}}>1$. The red line is the current limit circle. The blue line is the voltage limit circle. The magenta lines are the constant torque straight curves. The green line is the MTPA straight curve. The yellow line is the MTPV straight curve.

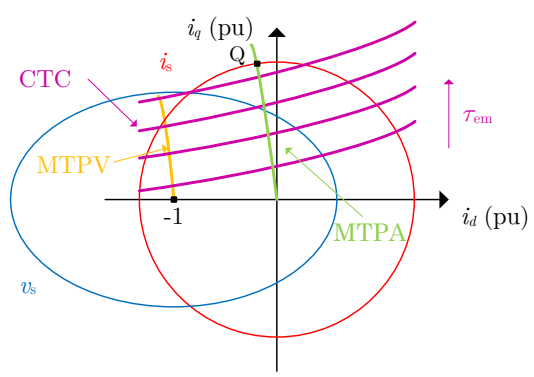

Fig. 3. Characteristic curves for IPMSMs with $i_{\mathrm{s}}>1$. The red line is the current limit circle. The blue line is the voltage limit ellipse. The magenta lines are the constant torque hyperbolic curves. The green line is the MTPA hyperbolic curve. The yellow line is the MTPV hyperbolic curve.

The torque curves, in the case of SPMSMs, are straight lines which only depend on the $i_{q}$ values as it is described in (10) with $\xi=1$. Nevertheless, in the case of IPMSMs, the torque curves are rectangular hyperbolas according to (10) with $\xi \neq 1$.

\section{B. LBEF trajectory and base speed in the polar coordinate system}

The attainable trajectories are different if the back electromotive force is lower or higher than the maximum synthesizable stator voltage. From now on, the first case is cited as Low Back Electromotive Force (LBEF) zone and the latter as FW zone. In [39, p. 303-327] some strategies at the LBEF zone have been compared: Constant Torque Angle Control (CTAC), Unit Power Factor Control (UPFC), Constant Stator Flux Control (CSFC) and MTPA.

In this paper, the MTPA algorithm is chosen to minimize the current needed for the demanded torque. This decision is supported by the necessity in vehicle applications to reduce the cross-sectional area of the cable conductors.

The MTPA condition for PMSMs is defined as $\frac{\partial \tau_{\mathrm{em}}}{\partial \gamma}=0$, expressing (10) in terms of $i_{\mathrm{s}}$ and $\gamma$. The MTPA angle value $\left(\gamma_{\text {MTPA }}\right)$ is expressed as

$$
\begin{gathered}
\gamma_{\mathrm{MTPA}}=\frac{\pi}{2} \\
\gamma_{\mathrm{MTPA}}=\arccos \left(\frac{-1+\sqrt{1+8 i_{\mathrm{s}}^{2}(1-\xi)^{2}}}{4 i_{\mathrm{s}}(1-\xi)}\right),
\end{gathered}
$$


represented in a green straight curve in Fig. 2 for SPMSMs (11) or in a green hyperbolic curve in Fig. 3 for IPMSMs (12).

The base speed is defined as the value when the voltage curve goes across the intersection point between the MTPA curve and the current circle (point Q in Fig. 2 and Fig. 3). From this value upwards, a FW technique has to be applied to maintain the work point inside the voltage curve. The stator voltage in the per-unit system at the base speed is expressed as

$$
\begin{gathered}
v_{\mathrm{s}}=\sqrt{i_{\mathrm{s}}^{2}+1} \\
v_{\mathrm{s}}=\sqrt{\frac{\left(-1+\sqrt{\left.1+8(1-\xi)^{2}\right)_{2}^{2}}\right)^{2}\left(1-\xi^{2}\right)}{16(\xi-1)^{2}}-\frac{-1+\sqrt{1+8(1-\xi)^{2} i_{s}^{2}}}{2(\xi-1)}+\left(1+\xi^{2} i_{\mathrm{s}}^{2}\right)},
\end{gathered}
$$

for SPMSM and IPMSM, respectively.

\section{Flux Weakening trajectories}

If the voltage curve center is located inside the current circle $\left(i_{\mathrm{s}}>1\right)$, then the theoretical maximum achievable speed is infinite, as long as the MTPV curve is followed and no electromagnetic and mechanical losses are considered. This is represented in yellow as a straight curve in Fig. 2 for SPMSMs or as a hyperbolic curve in Fig. 3 for IPMSMs. On the contrary, if the voltage curve center is located outside the current circle $\left(i_{\mathrm{s}}<1\right)$, then the maximum speed is finite at the point $\left(i_{d}, i_{q}\right)=\left(-i_{\mathrm{s}}, 0\right)$.

The MTPV trajectory is defined as the curve where the maximum torque at minimum current is achieved, considering the voltage limit. The MTPV condition for PMSMs is defined as $\frac{\partial \tau_{\mathrm{em}}}{\partial \delta}=0$, expressing (10) in terms of $i_{\mathrm{s}}$ and $\delta$. The MTPV current value $\left(i_{\mathrm{MTPV}}\right)$ is expressed as

$$
\begin{gathered}
i_{\mathrm{MTPV}}=\frac{1}{\cos (\gamma)} \\
i_{\mathrm{MTPV}}=\frac{-(2-\xi) \cos (\gamma)-\sqrt{(2-\xi)^{2} \cos ^{2}(\gamma)-4(1-\xi)\left(\cos ^{2}(\gamma)\left(\xi^{2}+1\right)-\xi^{2}\right)}}{2(1-\xi)\left(\cos ^{2}(\gamma)\left(\xi^{2}+1\right)-\xi^{2}\right)}
\end{gathered}
$$

for SPMSM and IPMSM, respectively.

At low speed, the motor can work at any point of the MTPA curve, and when the voltage curve crosses the MTPA zone, a FW strategy has to be applied, maintaining the stator voltage inside its limit. Depending on the torque level, there is a speed range in which the torque value can be maintained. This zone is named Constant Torque Control (CTC). To sum up, all possible strategies at the FW zone are based on the voltage limit condition: Current and Voltage Limit Control (CVLC), CTC, and MTPV.

Depending on the value of $i_{\mathrm{s}}$ different trajectories can be followed. If $i_{\mathrm{s}}>1$, then the motor can follow trajectory 1.1, 1.2 or 1.3, as it is depicted in Fig. 4. However, if $i_{\mathrm{s}}<1$, the motor can only follow trajectory 2.1 and 2.2 , as it is showed in Fig. 5.

\section{FluX-Weakening Strategy}

This section presents the control algorithm that calculates the $d q$-axis current set-points from the torque and speed references. The algorithm, represented in Fig. 6, smoothly changes among all trajectories explained in Section II-B and II-C, and

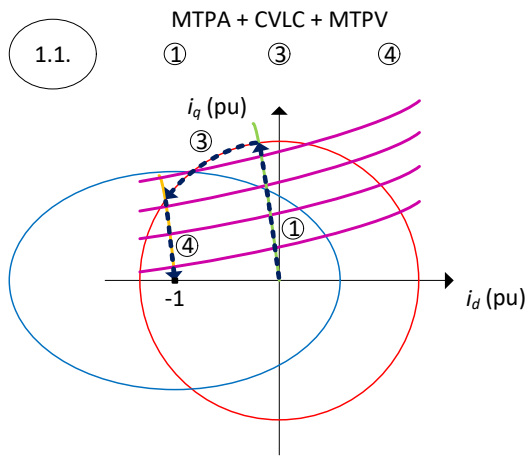

(a) Trajectory 1.1.

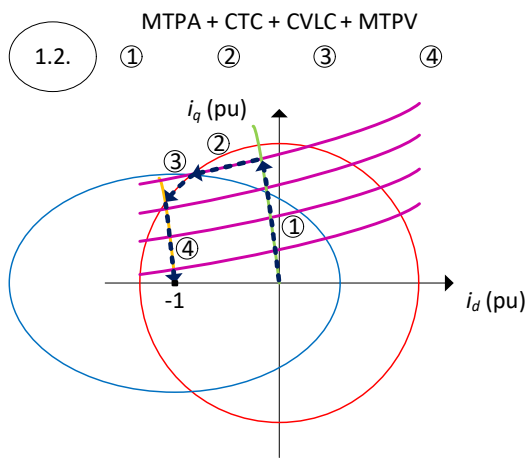

(b) Trajectory 1.2.

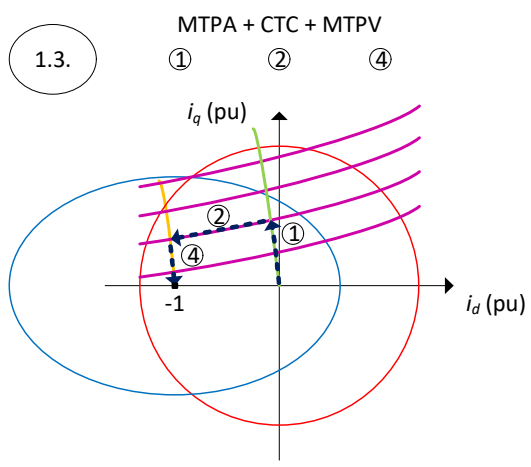

(c) Trajectory 1.3.

Fig. 4. Trajectories at MTPA and FW zones for IPMSMs if $i_{\mathrm{s}}>1$.

it allows the motor to work with torque and speed reference in a unified scheme. The per-unit system representation facilitates the implementation in a fixed-point microcontroller.

In Section III-A, the voltage control loop is explained. In Section III-B, the FW trajectory decision is analyzed. Finally, in Section III-C the speed control loop is presented.

\section{A. Voltage control loop}

The current regulators give the voltage feedback to the voltage control loop, in which the main objective is to maintain the voltage modulus lower than the voltage limit (9), considering a security factor $\left(K_{\mathrm{FW}}\right)$. The onset of the $\mathrm{FW}$ zone is determined when the voltage modulus exceeds the maximum value. 


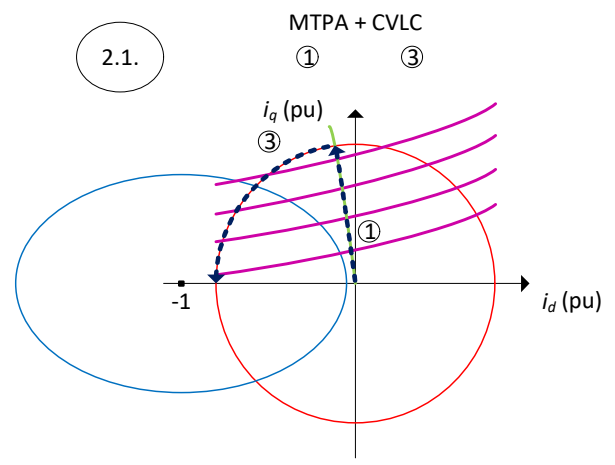

(a) Trajectory 2.1 .

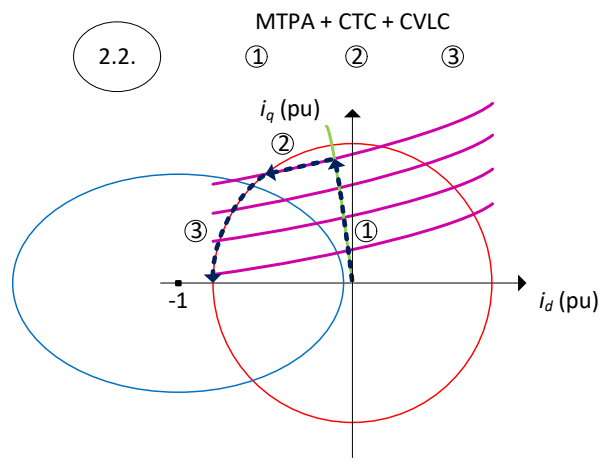

(b) Trajectory 2.2.

Fig. 5. Trajectories at MTPA and FW zones for IPMSMs if $i_{\mathrm{S}}<1$.

The voltage control loop of conventional methods manages $\Delta i_{d}$. Its main drawback is that $\Delta i_{d}$ has to increase at the same time that speed increases, except for the moment when the work point enters the MTPV trajectory for an IPMSM, when it has to decrease. This change on the PI control action for the same voltage error can be solved by changing the PI controller constants or letting an over-voltage during this transition. However, in the proposed method, the voltage control loop acts on $\Delta \gamma$, which always increases with speed, allowing the system to transition smoothly.

In this control scheme, $\Delta \gamma$, used to hold the work point inside the voltage limits, is added to $\gamma_{\mathrm{MTPA}}$ to achieve the current angle reference $\left(\gamma^{*}\right)$. The saturation blocks are added to guarantee that $\gamma^{*}$ stays in the range of $\left[\gamma_{\mathrm{MTPA}}, \pi\right]$.

\section{B. Flux Weakening trajectory decision}

The trajectory is chosen from the torque reference $\left(\tau_{\mathrm{em}}^{*}\right)$ and the current angle reference $\left(\gamma^{*}\right)$. Mainly, this decision is made thanks to two dynamic saturations that shrink the current modulus calculated to achieve the reference value.

Firstly, the current modulus needed for the required torque $\left(i_{\tau \mathrm{em}}\right)$ is calculated according to (10). From this value, $\gamma_{\text {MTPA }}$ is calculated following (12). Moreover, the current needed to work in the MTPV zone is calculated by replacing $\gamma$ for $\gamma^{*}$ into (16), so limiting to the maximum current specified in (7).

These saturations lead to a smooth transition among the attainable zones as is shown in Fig. 7. It depicts four different cases to get the minimum current:
TABLE III

IPMSM CHARACTERISTIC PARAMETERS

\begin{tabular}{lll}
\hline \hline Symbol & Value & \multicolumn{1}{c}{ Unit } \\
\hline$R_{\mathrm{s}}$ & 17 & $\mathrm{~m} \Omega$ \\
$L_{d}$ & 70 & $\mu \mathrm{H}$ \\
$L_{q}$ & 79 & $\mu \mathrm{H}$ \\
$\lambda_{\mathrm{m}}$ & 0.023 & $(\mathrm{~V} \cdot \mathrm{s}) / \mathrm{rad}$ \\
$V_{\text {bat }}$ & 48 & $\mathrm{~V}$ \\
$I_{\mathrm{s}, \max }$ & 467 & $\mathrm{~A}$ \\
$\mathrm{pp}$ & 20 & \\
\hline \hline
\end{tabular}

- $\gamma_{1} \rightarrow i_{\tau \mathrm{em}, 1}<i_{\mathrm{s}, 1}<i_{\mathrm{MTPV}, 1}:$ CTC

- $\gamma_{2} \rightarrow i_{\mathrm{s}, 2}<i_{\tau \mathrm{em}, 2}<i_{\mathrm{MTPV}, 2}$ : CVLC

- $\gamma_{3} \rightarrow i_{\mathrm{s}, 3}<i_{\mathrm{MTPV}, 3}<i_{\tau \mathrm{em}, 3}$ : CVLC

- $\gamma_{4} \rightarrow i_{\mathrm{MTPV}, 4}<i_{\mathrm{s}, 4}<i_{\tau \mathrm{em}, 4}$ : MTPV

\section{Speed control loop}

The speed control loop independently acts to the torque reference through a PI controller that limits the speed to the reference value $\left(\Omega_{\mathrm{m}}^{*}\right)$, enabling the motor to work in the Constant Speed Control (CSC) zone. The current mechanical speed in pu $\left(\Omega_{\mathrm{m}}\right)$ is calculated from $\Omega_{\mathrm{e}}$ using (5). The PIcontroller output is used to limit the torque reference, acting as the upper torque saturation. The main advantage is that the dynamics of the rest of the control is not affected by the speed PI controller. It only takes action when the vehicle has the CSL switched on.

\section{Simulation Results}

Initially, an analytical study is carried out to compare the accomplishment of the proposed FW method compared with the conventional method. A direct drive IPMSM, which runs as the rear wheel of an e-motorbike, is used. The characteristic parameters are listed in Table III. The main parameters to define its characteristic curves, in the per unit-system, are $\xi=1.1$ and $i_{\mathrm{s}}=1.4$.

Fig. 8 shows the torque-speed and power-speed curves corresponding to the conventional (MTPA + CVLC) and the proposed (MTPA + CVLC + MTPV) methods. The electromagnetic power is defined in the secondary y-axis as $p_{\mathrm{em}}$. The proposed method achieves constant power during a wide speed range from $\omega_{\mathrm{e}}=1.7 \omega_{\mathrm{b}}$. Meanwhile, the output power decreases until it reaches 0 from this speed to $\omega_{\mathrm{e}}=4.2 \omega_{\mathrm{b}}$ in the conventional method. So, the presented algorithm obtains torque during more speed range, therefore adapting to the electric vehicle needs.

Fig. 9 shows the evolution of $i_{d}$ and $\gamma$ regarding speed. Fig. 9a displays how $i_{d}$ totally inverts its dynamics from $\omega_{\mathrm{e}}=1.7 \omega_{\mathrm{b}}$. This operation derivates in a vortex evolution seen in the $d q$-trajectory, implying a higher value of $K_{\mathrm{FW}}$. Meanwhile, Fig. $9 \mathrm{~b}$ shows the continuous increase of $\Delta \gamma$. That is why the proposed voltage PI controller controls $\Delta \gamma$.

A Matlab-Simulink model is designed to validate the proposed method. A step torque reference of $1.1 \mathrm{pu}$, less than 


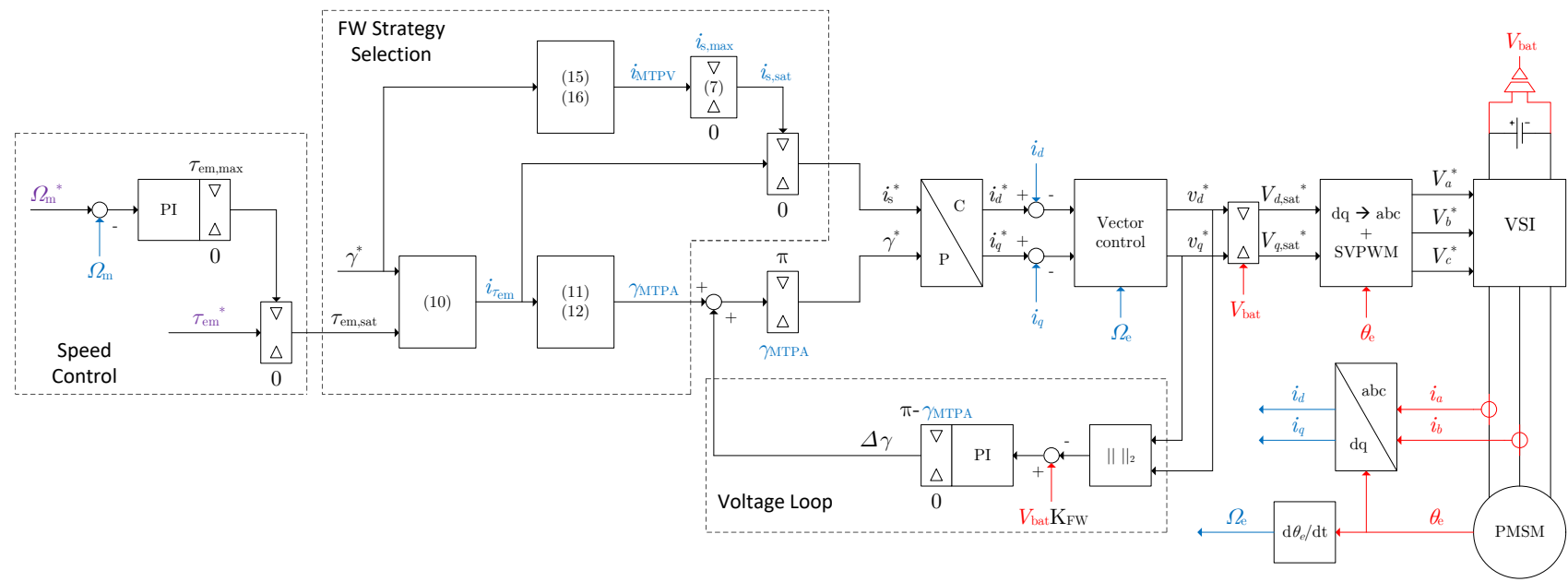

Fig. 6. Control Algorithm Model. The reference values are represented in purple. The feedback values from the system are shown in red. The intermediate calculations are depicted in blue.

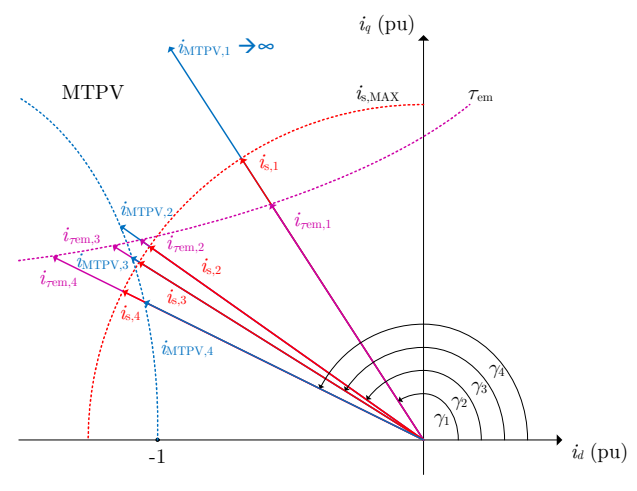

Fig. 7. Current Vector Selection for an IPMSM.

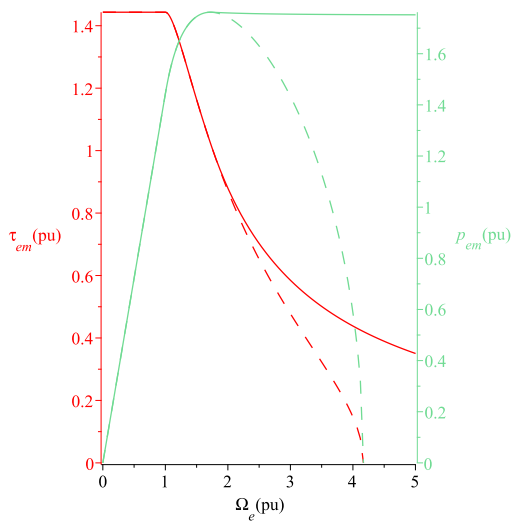

Fig. 8. Torque versus speed (red) and power versus speed (green) with conventional (dashed line) and proposed (solid line) FW methods.

the maximum value, with a speed limit of $1.31 \mathrm{pu}$, is applied, demonstrating that the proposed method can work in all possible trajectories. Fig. 10 demonstrates the control algorithm efficacy through the simulated $d q$-trajectory. Initially, the work point, represented by a cyan line, follows the MTPA strategy. Then, the speed increases, and the control forces to steadily

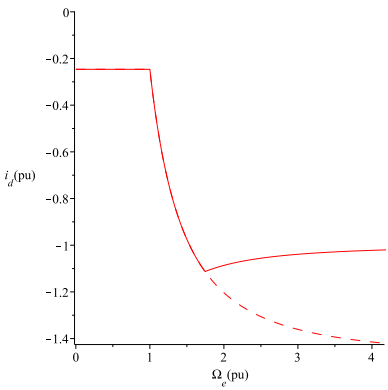

(a)

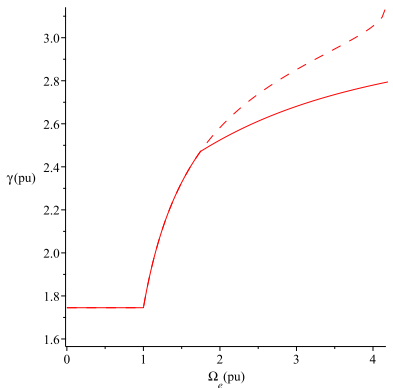

(b)
Fig. 9. Control variable of voltage PI controller versus speed with conventional (dashed line) and proposed (solid line) FW methods.

raise the angle $\gamma$, following the curves CTC, CVLC, and MTPV. From a specific speed value, the work point pursues the voltage ellipse, decreasing the applied torque, until the break-even point is reached.

Fig. 11 shows the torque response, analyzing the different trajectories in terms of torque. During the MTPA and CTC zones, the electric motor can apply the torque reference, whereas it can not do so in the CVLC, MTPV, and CSC zones because it maintains the work point inside the ellipse voltage. Finally, the applied torque is reduced until the system reaches the mechanical balance to comply with the speed limit, as can be seen in Fig. 12.

\section{EXPERIMENTAL RESUlTS}

To verify the reliability of the method, as shown in Fig. 13, an experimental platform which has a DC motor as its load is set up. The test bench is composed of a $6.5 \mathrm{~kW}$ three-phase inverter, fed from a rated $48 \mathrm{~V}$ Lithium-ion battery, and a $2.5 \mathrm{~kW}$ and $510 \mathrm{rpm}$ IPMSM. The inverter is managed by a fixed-point microcontroller where the algorithm has been implemented. The torque reference is given by a real throttle to emulate the operation of an electric motorbike. 


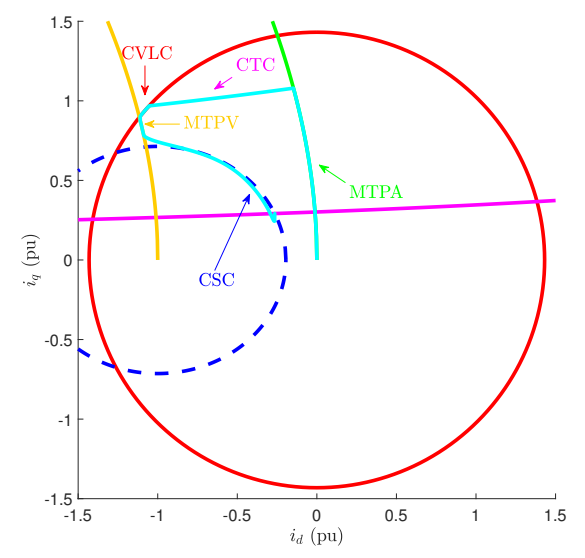

Fig. 10. Representation in $d q$-axis of current limit (red), MTPA trajectory (green), MTPV trajectory (yellow), torque in steady-state (magenta), voltage ellipse considering the resistor drop at speed reference (blue), and simulated $d q$-trajectory (cyan).

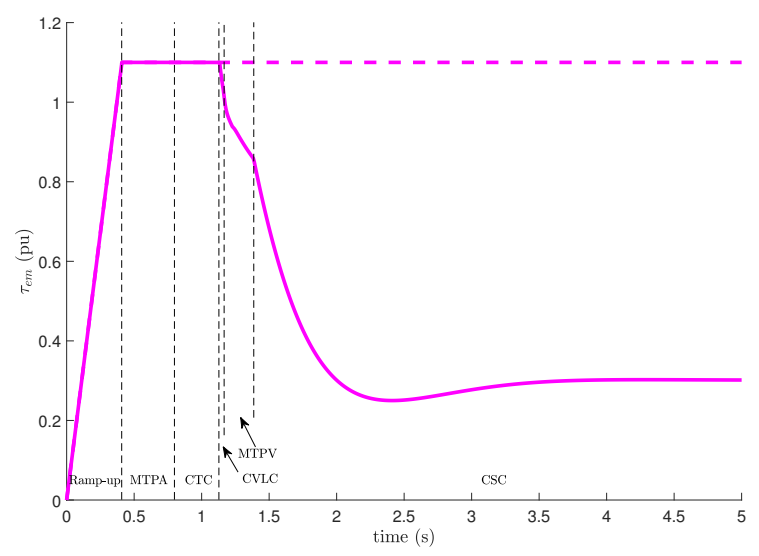

Fig. 11. Simulation results of torque versus time. Torque reference (magenta, dashed line) and applied torque (magenta, solid line).

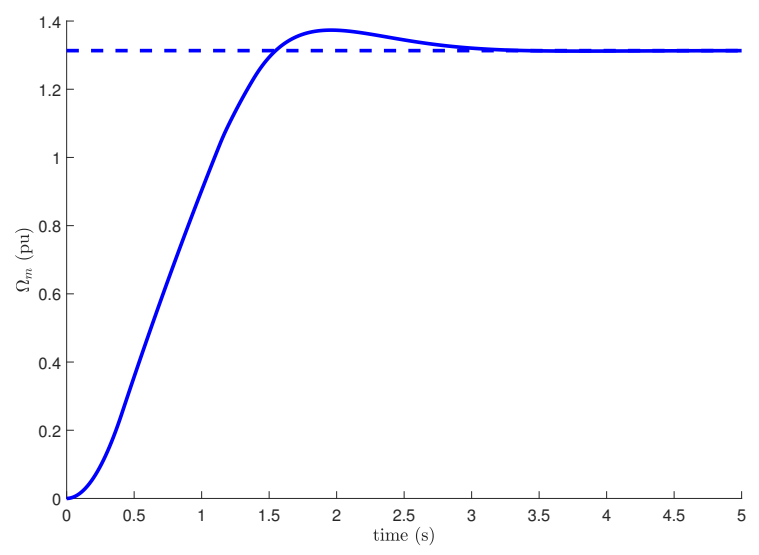

Fig. 12. Simulation results of mechanical speed versus time. Speed limit (blue, dashed line) and real speed (blue, solid line).

The motor can not work either at CVLC or MTPV zones due to the limitation of the elements available in the laboratory.

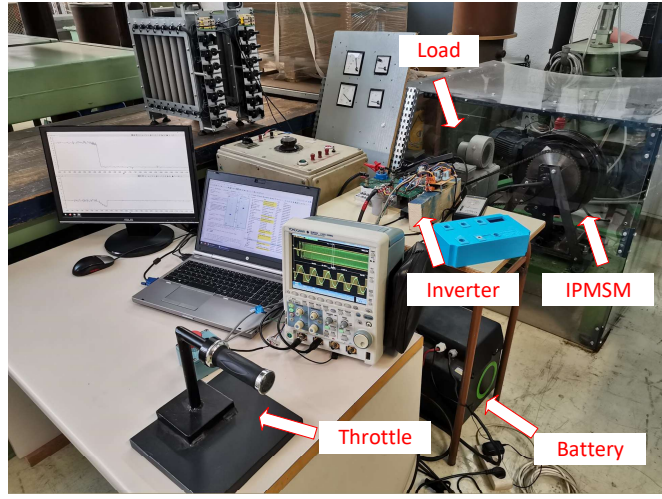

Fig. 13. Experimental setup of the IPMSM assembled with a DC motor, having the throttle signal as torque reference.

The real system has not enough inertia to accelerate slowly. As a consequence, if a high reference torque is applied, the motor rapidly accelerates to the speed limit. In Section IV, the inertia parameter is ten times higher than its real value, which is used in Section V, with the purpose to verify the effectiveness of the algorithm in all the speed range.

Initially, a step torque reference of $0.18 \mathrm{pu}$ is applied to the machine. Also, the speed limit is fixed to $1.31 \mathrm{pu}$. At time $2 \mathrm{~s}$, the torque reference is increased up to $0.36 \mathrm{pu}$; meanwhile, the speed limit is kept unchanged. At time $4 \mathrm{~s}$, to analyze the performance of the voltage loop controller, the load is reduced in a third. The results are reported in Fig. 14 to Fig. 19.

Fig. 14 shows the work point in the $d q$ plane. When the motor works below its base speed, the work point is sustained at the MTPA curve. If the speed reaches the limit at which a flux-weakening algorithm is needed, the voltage control loop increases the current angle, and the algorithm lets the motor to maintain the torque reference. Despite that, when the speed reference is overtaken, the reference torque is reduced until the speed reaches this value. At the moment the load is lessened in a third, the work point moves along the same ellipse, but the intersection point corresponds with a torque curve lower than previously.

Fig. 15 shows both the $d q$-axis reference and applied values. Until time $2.2 \mathrm{~s}$, the work point resides in the MTPA curve, but once the speed increases until the voltage limit is achieved, the current angle rises by increasing the $d$-axis current following the CT zone. At time $2.6 \mathrm{~s}$, the constant torque can not be followed, and the speed limit constraints the applied torque by reducing both the $d q$-axis currents. At time $4 \mathrm{~s}$, as the load is decreased and to maintain the speed limit, the $d q$-axis currents are diminished to reduce the applied torque.

Fig. 16 shows the experimental phase currents during the test. Fig. 16a gives a notion of how the phase currents are modified during the transition between LBEF and FW zones, and when the work point works at a constant speed, including the load variation. Fig. 16b presents the transition between the Six-Step to the Continuous commutation mode. The electrical angle goes from a discrete to a continuous representation, by following a Linear Regression from the Least Squares Method explained in [40].

Fig. 17 shows the voltage waveform versus time. As can 


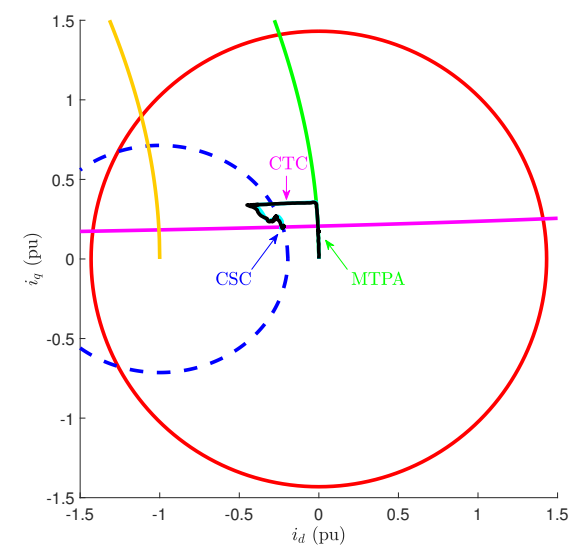

Fig. 14. Representation in $d q$-axis of current limit (red), MTPA trajectory (green), MTPV trajectory (yellow), torque curve in steady-state (magenta), voltage ellipse considering the resistor drop at speed reference (blue), and simulated (cyan) and experimental (black) $d q$-trajectory.
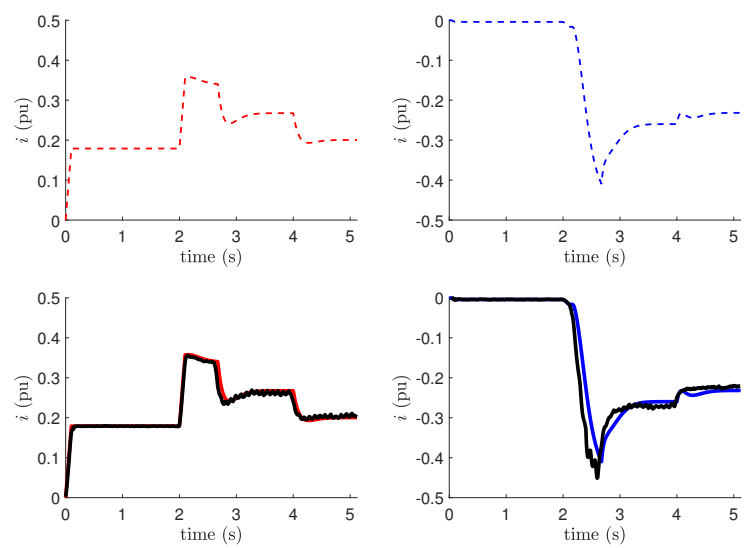

Fig. 15. Comparison between the simulation and experimental results of the evolution of $d q$-axis current versus time. $d q$-axis current reference (blue and red, dashed line), simulation results (blue and red, solid line), and experimental results (black).

be seen at time $2.2 \mathrm{~s}$, the voltage modulus gets its maximum value $\left(V_{\text {bat }} K_{\mathrm{FW}}\right)$. From that point, a flux-weakening technique is applied to maintain the voltage down this value. An adequate $\left(K_{\mathrm{FW}}\right)$ factor is essential to maintain the stability of the system control because there is a transient when the applied voltage is higher than its reference.

Fig. 18 shows the applied torque evolution at each zone. Until the maximum speed is not reached, the reference torque is applied. From that point, the applied torque decreases to maintain the speed limit even when the load torque is lessened.

Fig. 19 exhibits the evolution of the mechanical speed either in the simulation and the real model. The transition between the Six-Step mode and the Continuous mode provokes a slipping in the mechanical system between the test motor and the load, as can be seen at the beginning. At time $2.6 \mathrm{~s}$, the speed limit is overcome until the applied torque is not reduced enough. At time $4 \mathrm{~s}$, the load change lets to increase the speed until the applied torque is not reduced again.

To overcome the physical limitations of the setup, a Virtual

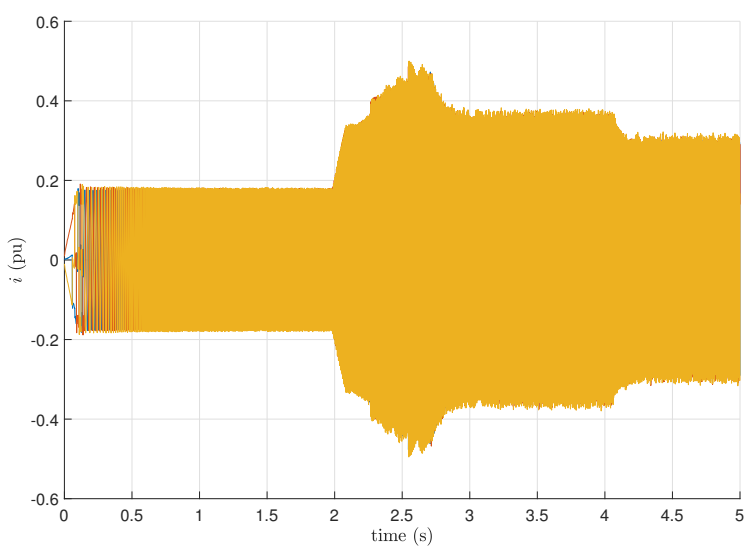

(a) Entire phase current waveforms.

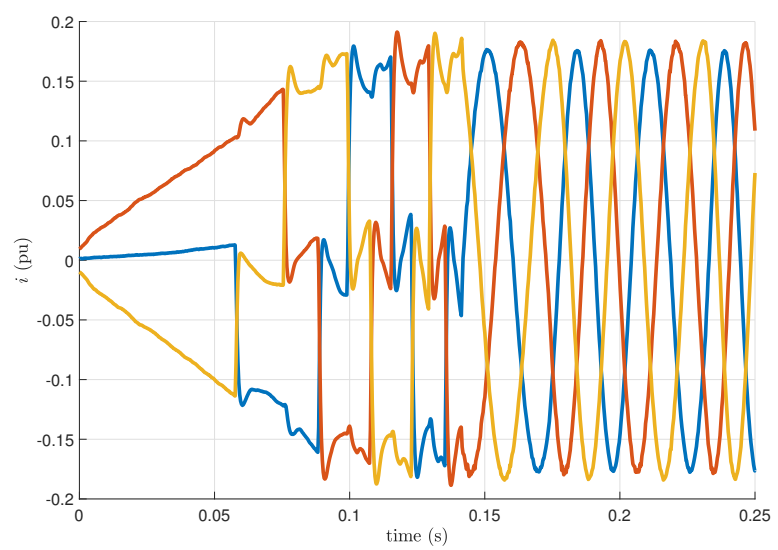

(b) Zoom at the starting.

Fig. 16. Representation of phase current waveforms regarding time. Experimental phase A, B, and C currents represented in blue, orange and yellow waveforms, respectively.

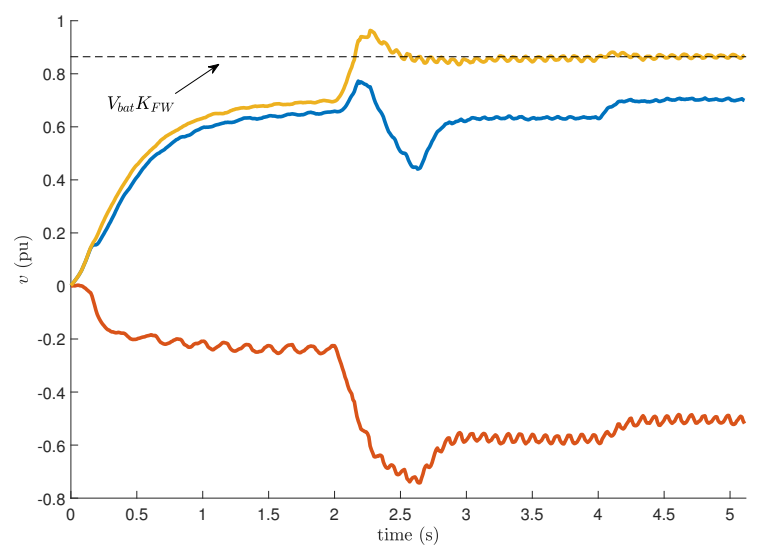

Fig. 17. Experimental results of $d q$-axis voltage and modulus regarding time. $d q$-axis and modulus voltage experimental results in orange, blue and yellow, respectively. The black dashed line indicates the flux-weakening voltage limit.

CVLC zone and MTPV zone, called VCVLC and VMTPV, respectively, have been programmed in the power inverter. Mainly, these modifications are done by reducing the real $I_{\mathrm{sc}}$ 


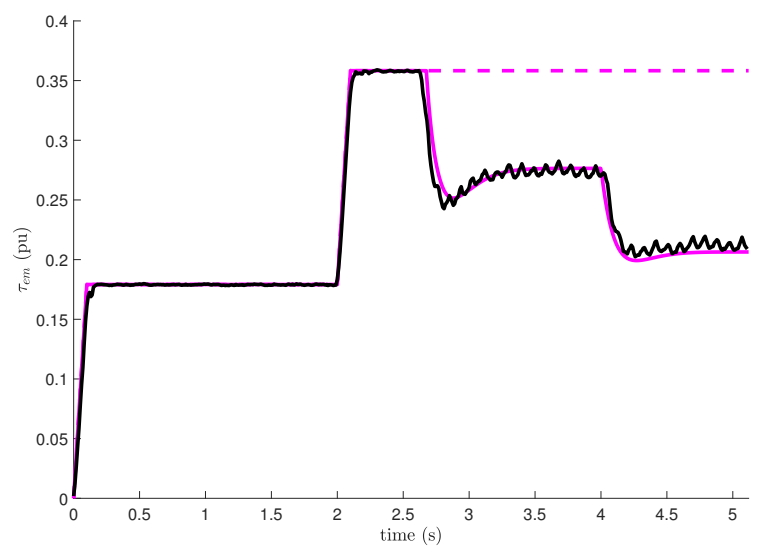

Fig. 18. Comparison between the simulation and experimental results of the evolution of torque versus time. Torque reference (magenta, dashed line), simulation results (magenta, solid line), and experimental results (black).

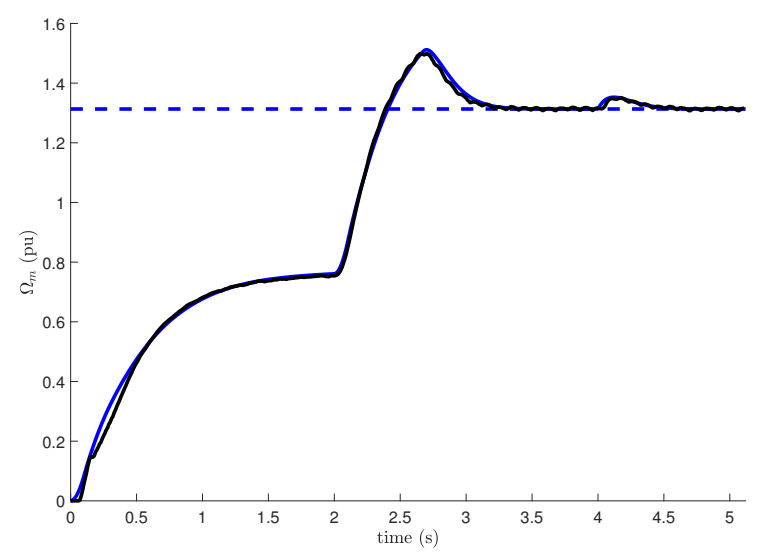

Fig. 19. Comparison between the simulation and experimental results of the evolution of speed versus time. Speed reference (blue, dashed line), simulation results (blue, solid line), and experimental results (black).

and $I_{\mathrm{s}, \max }$ to the virtual ones. It becomes in a hyperbola that represents the VMTPV zone nearer to the $q$-axis, and in a current limit circle that is shrunk to its center compared with the original circle. Fig. 20 shows the work point in the $d q$ plane both for the conventional method (cyan line) and the proposed algorithm (black line). The proposed algorithm demonstrates its smooth performance to work from the MTPA zone to the FW zone, and also when changing from CTC, VCVLC, and VMTPV regions.

Therefore, the experimental results confirmed that the proposed method can work at all possible trajectories, if the virtual ones are considered. Moreover, it changes the chosen strategy smoothly, without switching between each of them, by adapting the control algorithm to the necessity of an electric vehicle, which has both the set-point from the gas pedal and CSL. The presented results in this article assure the correct operation of the voltage loop in conjunction with the speed regulator.

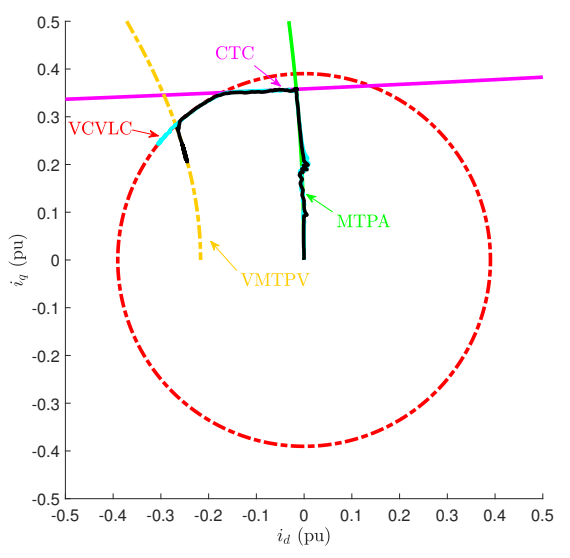

Fig. 20. Representation in $d q$-axis of virtual current limit (dash-dot red), MTPA trajectory (green), VMTPV trajectory (dash-dot yellow), torque reference curve (magenta), and conventional (cyan) and proposed (black) $d q$ trajectory.

\section{CONCLUSION}

This paper has proposed an advanced flux-weakening control algorithm focused on the requirements of mild-hybrid and full-electric vehicles. The main feature of this method is to unify the torque and speed controllers without interfering between them until the maximum speed is reached. Besides, it exploits the polar coordinate representation and the perunit system for generating the current vector reference. Furthermore, it smoothly changes the reference signals coming from the vehicle, beginning with the torque reference from the accelerator pedal up to the speed limit from the cruise speed limiter, according to the most confining signal.

Moreover, the algorithm can be used both for SPMSMs and IPMSMs, and it works in all possible trajectories as Maximum Torque per Ampere, Constant Torque, Current and Voltage Limit, Maximum Torque per Voltage, and Constant Speed with a smooth transition between the Low Back Electromotive Force and the Flux Weakening zones. This transition is managed by a voltage control loop which considers either the resistor voltage drop or the saturation effects.

Both simulation and experimental results prove the reliability and effectiveness of this algorithm on a $2.5 \mathrm{~kW}$ and $510 \mathrm{rpm}$ IPMSM in a direct-drive e-motorbike of a $48-\mathrm{V}$ system.

\section{REFERENCES}

[1] T. Finken, M. Felden, and K. Hameyer, "Comparison and design of different electrical machine types regarding their applicability in hybrid electrical vehicles," Proceedings of the 2008 International Conference on Electrical Machines, ICEM'08, DOI 10.1109/ICELMACH.2008.4800044, pp. 1-5, 2008.

[2] L. Sepulchre, M. Fadel, M. Pietrzak-David, and G. Porte, "Fluxweakening strategy for high speed PMSM for vehicle application," in 2016 International Conference on Electrical Systems for Aircraft, Railway, Ship Propulsion and Road Vehicles and International Transportation Electrification Conference, ESARS-ITEC 2016, DOI 10.1109/ESARS-ITEC.2016.7841413, 2017.

[3] S. Morimoto, M. Sanada, and Y. Takeda, "Wide-Speed Operation of Interior Permanent Magnet Synchronous Motors with High-Performance Current Regulator," IEEE Transactions on Industry Applications, vol. 30, DOI 10.1109/28.297908, no. 4, pp. 920-926, 1994. 
[4] S. Sudhoff, K. Corzine, and H. Hegner, "A Flux-Weakening Strategy for Current-Regulated Surface-Mounted Permanent-Magnet Machine Drives," IEEE Transactions on Energy Conversion, vol. 10, no. 3, pp. 431-437, 1995.

[5] M. Meyer, T. Grote, and J. Böcker, "Direct torque control for interior permanent magnet synchronous motors with respect to optimal efficiency," in 2007 European Conference on Power Electronics and Applications, EPE, DOI 10.1109/EPE.2007.4417370, pp. 1-9, 2007.

[6] W. Peters, T. Huber, and J. Böcker, "Control Realization for an Interior Permanent Magnet Synchronous Motor (IPMSM) in Automotive Drive Trains," in International Exhibition and Conference for Power Electronics, Intelligent Motion, Renewable Energy and Energy Management (PCIM Europe), pp. 2-7, 2011.

[7] T. Huber, W. Peters, and J. Bocker, "Voltage controller for flux weakening operation of interior permanent magnet synchronous motor in automotive traction applications," in Proceedings - 2015 IEEE International Electric Machines and Drives Conference, IEMDC 2015, DOI 10.1109/IEMDC.2015.7409195, pp. 1078-1083, 2016.

[8] L. Zhu, S. Xue, X. Wen, Y. Li, and L. Kong, "A new deep field-weakening strategy of IPM machines based on single current regulator and voltage angle control," in 2010 IEEE Energy Conversion Congress and Exposition, ECCE 2010 - Proceedings, DOI 10.1109/ECCE.2010.5617844, pp. 1144-1149, 2010.

[9] Y. Zhang, L. Xu, M. K. Güven, S. Chi, and M. Illindala, "Experimental verification of deep field weakening operation of a 50-kW IPM machine by using single current regulator," IEEE Transactions on Industry Applications, vol. 47, DOI 10.1109/TIA.2010.2091478, no. 1, pp. 128133, 2011.

[10] T. Hu, F. Lin, L. Cui, Q. Yuan, and Z. Yang, "The flux-weakening control of interior permanent magnet synchronous traction motors for highspeed train," in Proceedings of the 1st IWHIR, vol. 1, DOI 10.1007/9783-642-27960-7-40, pp. 451-461, 2012.

[11] T. S. Kwon, G. Y. Choi, M. S. Kwak, and S. K. Sul, "Novel flux-weakening control of an IPMSM for quasi-six-step operation," IEEE Transactions on Industry Applications, vol. 44, DOI 10.1109/TIA.2008.2006305, no. 6, pp. 1722-1731, 2008.

[12] P. Y. Lin and Y. S. Lai, "Voltage Control Technique for the Extension of DC-Link Voltage Utilization of Finite-Speed SPMSM Drives," IEEE Transactions on Industrial Electronics, vol. 59, DOI 10.1109/TIE.2011.2173095, no. 9, pp. 3392-3402, 2012.

[13] I. Boldea, M. C. Paicu, and G. D. Andreescu, "Active flux concept for motion-sensorless unified AC drives," IEEE Transactions on Power Electronics, vol. 23, DOI 10.1109/TPEL.2008.2002394, no. 5, pp. 26122618,2008

[14] G. Pellegrino, R. I. Bojoi, and P. Guglielmi, "Unified direct-flux vector control for AC motor drives," IEEE Transactions on Industry Applications, vol. 47, DOI 10.1109/TIA.2011.2161532, no. 5, pp. 2093-2102, 2011.

[15] Jang-Mok Kim and Seung-Ki Sul, "Speed control of interior permanent magnet synchronous motor drive for the flux weakening operation," IEEE Transactions on Industry Applications, vol. 33, DOI 10.1109/28.567075, no. 1, pp. 43-48, 1997.

[16] N. Bianchi, S. Bolognani, and M. Zigliotto, "High-performance PM synchronous motor drive for an electrical scooter," IEEE Transactions on Industry Applications, vol. 37, DOI 10.1109/28.952510, no. 5, pp. $1348-1355,2001$.

[17] J. Wai and T. Jahns, "A new control technique for achieving wide constant power speed operation with an interior PM alternator machine," in Conference Record of the 2001 IEEE Industry Applications Conference. 36th IAS Annual Meeting, DOI 10.1109/IAS.2001.955545, pp. 807-814, 2001.

[18] M. Kim, J. S. Yim, S. K. Sul, and S. I. Lim, "Implementation of super high-speed permanent magnet synchronous machine drive," in 2009 IEEE Energy Conversion Congress and Exposition, ECCE 2009, DOI 10.1109/ECCE.2009.5316187, pp. 1700-1704. IEEE, 2009.

[19] J. Li, Q. Wang, J. Yu, and J. Xiong, "Field-weakening Control Algorithm for Interior Permanent Magnet Synchronous Motor Based on SpaceVector Modulation Technique," Journal of Convergence Information Technology, vol. 8, DOI 10.4156/jcit.vol8.issue3.20, no. 3, pp. 167-175, 2013.

[20] S. Bolognani, S. Calligaro, and R. Petrella, "Adaptive Flux-Weakening Controller for Interior Permanent Magnet Synchronous Motor Drives," IEEE Journal of Emerging and Selected Topics in Power Electronics, vol. 2, DOI 10.1109/JESTPE.2014.2299153, no. 2, pp. 236-248, 2014.

[21] S. Bozhko, M. Rashed, C. I. Hill, S. S. Yeoh, and T. Yang, "FluxWeakening Control of Electric Starter-Generator Based on Permanent-
Magnet Machine," IEEE Transactions on Transportation Electrification, vol. 3, DOI 10.1109/TTE.2017.2718221, no. 4, pp. 864-877, 2017.

[22] P. Vaclavek and P. Blaha, "Interior permanent magnet synchronous machine field weakening control strategy - The analytical solution," in Proceedings of the SICE Annual Conference, DOI 10.1109/SICE.2008.4654756, pp. 753-757, 2008.

[23] N. V. Olarescu, M. Weinmann, S. Zeh, and S. Musuroi, "Novel flux weakening control algorithm for PMSMS," in POWERENG 2009 - 2nd International Conference on Power Engineering, Energy and Electrical Drives Proceedings, DOI 10.1109/POWERENG.2009.4915216, pp. 123-127, 2009

[24] A. Sanz, E. Oyarbide, R. Gálvez, C. Bernal, P. Molina, and I. S. Vicente, "Analytical maximum torque per volt control strategy of an interior permanent magnet synchronous motor with very low battery voltage," IET Electric Power Applications, vol. 13, DOI 10.1049/ietepa.2018.5469, no. 7, pp. 1042-1050, 2019.

[25] Y. Z. Chen, Y. T. Fang, X. Y. Huang, and J. Zhang, "Torque and Flux Weakening Control with MTPV for Interior Permanent Magnet Synchronous Motor," in 2016 IEEE Vehicle Power and Propulsion Conference, VPPC 2016 - Proceedings, DOI 10.1109/VPPC.2016.7791804, 2016.

[26] S. Wang, J. Kang, M. Degano, A. Galassini, and C. Gerada, "An Accurate Wide-Speed Range Control Method of IPMSM Considering Resistive Voltage Drop and Magnetic Saturation," IEEE Transactions on Industrial Electronics, vol. 67, DOI 10.1109/tie.2019.2912766, no. 4, pp. 2630-2641, 2020.

[27] S. M. S. I. Shakib, S. Member, D. Xiao, R. Dutta, K. S. Alam, I. Osman, and S. Member, "An Analytical Approach to Direct Torque and Flux Control of Interior Permanent Magnet Synchronous Machine for Deep Field Weakening Without Using Pre-calculated Lookup Tables," in 10th International Conference on Power Electronics - ECCE Asia, pp. 1-6, 2019.

[28] L. Huang, C. Zhao, and P. Huang, "An approach to improve the torque performance of IPMSM by considering cross saturation applied for hybrid electric vehicle," in 2010 International Conference on Electrical Machines and Systems, ICEMS2010, pp. 1378-1381, 2010

[29] M. S. Kunter, T. Schoenen, W. Hoffmann, and R. W. De Doncker, "IPMSM control regime for a hybrid-electric vehicle application," in 2010 Emobility - Electrical Power Train, EEPT 2010, DOI 10.1109/EMOBILITY.2010.5668054, pp. 1-5. IEEE, 2010.

[30] S. Ekanayake, R. Dutta, M. Rahman, and M. X. Bui, "Performances of a Fractional-Slot Concentrated-Winding Permanent Magnet Synchronous Machine under Position Sensorless Control in Deep Fluxweakening Region," IEEE Transactions on Industry Applications, DOI 10.1109/tia.2019.2931269, pp. 1-9, 2019.

[31] H. Liu, Z. Q. Zhu, E. Mohamed, Y. Fu, and X. Qi, "Flux-weakening control of nonsalient pole PMSM having large winding inductance, accounting for resistive voltage drop and inverter nonlinearities," IEEE Transactions on Power Electronics, vol. 27, DOI 10.1109/TPEL.2011.2159398, no. 2, pp. 942-952, 2012

[32] D. Hu, L. Zhu, and L. Xu, "Maximum Torque per Volt operation and stability improvement of PMSM in deep flux-weakening Region," in 2012 IEEE Energy Conversion Congress and Exposition, ECCE 2012, DOI 10.1109/ECCE.2012.6342675, pp. 1233-1237. IEEE, 2012.

[33] P. Y. Lin, W. T. Lee, S. W. Chen, J. C. Hwang, and Y. S. Lai, "Infinite speed drives control with MTPA and MTPV for interior permanent magnet synchronous motor," in IECON Proceedings (Industrial Electronics Conference), DOI 10.1109/IECON.2014.7048572, pp. 668-674, 2014.

[34] J. Li, S. Ekanayake, M. F. Rahman, R. Dutta, X. Huang, J. Ma, and Y. Fang, "Deep flux weakening control with six-step overmodulation for a segmented interior permanent magnet synchronous motor," in 2017 20th International Conference on Electrical Machines and Systems, ICEMS 2017, DOI 10.1109/ICEMS.2017.8056517, pp. 1-6, 2017.

[35] N. Pothi, "Improvement of flux-weakening control of surface mounted permanent magnet synchronous machine considering inverter nonlinearity," in 2017 International Electrical Engineering Congress, iEECON 2017, DOI 10.1109/IEECON.2017.8075736, pp. 1-4, 2017.

[36] Y. Xu, W. Zhang, and D. Sun, "Comparative research of two fluxweakening method of PMSMs in high speed range," in 2017 20th International Conference on Electrical Machines and Systems, ICEMS, DOI 10.1109/ICEMS.2017.8056218, pp. 1-5, 2017.

[37] L. Sepulchre, M. Fadel, M. Pietrzak-David, and G. Porte, "MTPV FluxWeakening Strategy for PMSM High Speed Drive," IEEE Transactions on Industry Applications, vol. 54, DOI 10.1109/TIA.2018.2856841, no. 6, pp. 6081-6089, 2018.

[38] V. Manzolini, D. Da Ru, and S. Bolognani, "An Effective Flux Weakening Control of a SyRM Drive Including MTPV Opera- 
tion," IEEE Transactions on Industry Applications, vol. 55, DOI 10.1109/TIA.2018.2886328, no. 3, pp. 2700-2709, 2019.

[39] R. Krishnan, Permanent Magnet Synchronous and Brushless DC Motor Drives, T. . F. Group, Ed. Virgina, USA: CRC Press, 2010.

[40] X. Zhang and W. Zhang, "An Improved Rotor Position Estimation in PMSM with Low-Resolution Hall-Effect Sensors," in 2014 17th International Conference on Electrical Machines and Systems, ICEMS, DOI 10.1109/TIE.2010.2098367, pp. 2722-2727, 2014.

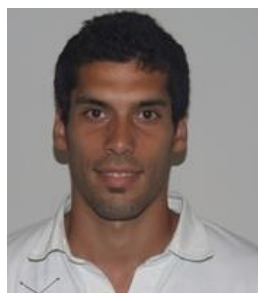

Carlos Miguel Espinar was born in L'Hospitalet de Llobregat, Spain, in 1985. He received the MSc. degree in Electrical Engineering from the Escola Tècnica Superior d'Enginyeria Industrial de Barcelona (ETSEIB), at the Universitat Politècnica de Catalunya (UPC) in 2011. Since 2011 he is working at the Centre d'Innovació Tecnològica en Convertidors Estàtics i Accionaments (CITCEAUPC) as a senior engineer to develop new prototypes that are focused on controlling Permanent Magnet Synchronous Machines (PMSM) for different applications such as fan, washing machines or wave energy extraction. Also, he is engaged in the development of new control algorithms for these motors, which are embedded in electrical and mild-hybrid vehicles. His main research is the design and control of PMSMs and the design of power converters for induction heating applications. He is currently working towards the Ph.D degree at the Universitat Politècnica de Catalunya, Barcelona, Spain, to develop new control algorithms for PMSMs in electric vehicles.

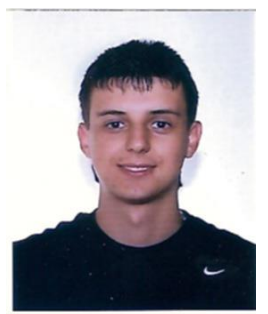

Daniel Heredero Peris was born in Vilanova i la Geltrú, Spain, in 1985. He received the MSc. degree in Control Engineering and Ph.D. from the Escola Tècnica Superior d'Enginyeria Industrial de Barcelona (ETSEIB), Universitat Politècnica de Catalunya (UPC) in 2010 and 2017. Since 2010 he is working with Centre d'Innovació Tecnològica en Convertidors Estàtics i Accionaments (CITCEAUPC) as a project engineer developing tasks focused on the design of algorithms related to the control of grid-connected and standalone single/three-phase inverters, and $\mathrm{V} 2 \mathrm{G}$ projects for $\mathrm{EV}$. His main research interests are control of power electronics, micro-grids and EVs.

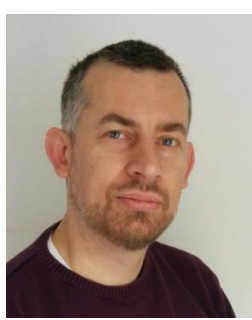

Gabriel Gross was born in Ibiza, Spain, in 1979. $\mathrm{He}$ received his MSc. degree in Electrical Engineering from the Escola Tècnica Superior d'Enginyeria Industrial de Barcelona (ETSEIB), at the Universitat Politècnica de Catalunya (UPC), in 2004. Since then he is working at CITCEA-UPC developing R\&D projects for the industry in various areas: electronics, power electronics, digital control and communications, electric machine design, and others. First as a project engineer (2005-2008), then as project manager (2009-2011) and later as team manager (2012 now). His primary research interest are power electronics and digital control, focused on electric motor control.

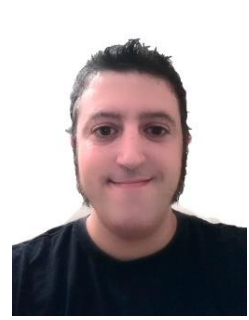

Marc Llonch Masachs was born in Terrassa, Spain, in 1978. He received the MSc. degree in Industrial Engineering from the Escola Tècnica Superior d'Enginyeria Industrial de Barcelona (ETSEIB), at Universitat Politècnica de Catalunya (UPC) in 2014. Since 2014 he is working with Centre d'Innovació Tecnològica en Convertidors Estàtics i Accionaments (CITCEA-UPC) as a project engineer carrying out tasks focused on the development of grid connected and standalone converters for DERs and EVs. His main research interest is focused in the power electronic knowledge at the service of micro-grids and EVs.

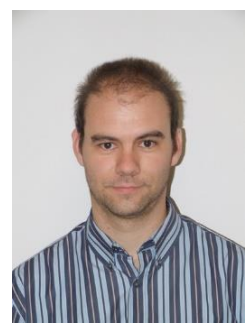

Daniel Montesinos-Miracle (S'01-M'08-SM'12) was born in Barcelona, Spain, in 1975. He received the MSc. degree in Electrical Engineering from the Escola Tècnica Superior d'Enginyeria Industrial de Barcelona (ETSEIB), Technical University of Catalonia (UPC), Barcelona, Spain, in 2000, and $\mathrm{PhD}$ degree from the Universitat Politècnica de Catalunya (UPC), in 2008. In 2001 he joined Salicru Electronics, S.A., Santa Maria de Palautordera, Spain as a research and development engineer. Since 2001 he has been involved in the Centre of Technological Innovation in Static Converters and Drives (CITCEA-UPC) as a research collaborator. In 2005 he becomes a lecturer at Electrical Engineering Department, Polytechnic University of Catalonia (UPC). Since 2012 he is an Associate Professor at UPC. He has become the CITCEA-UPC director in 2016. In 2012, he has co-founded teknoCEA, a spin-off company providing components, systems and services for power electronics research and manufacturing. His primary research interests are power electronics, drives and green energy converters. 